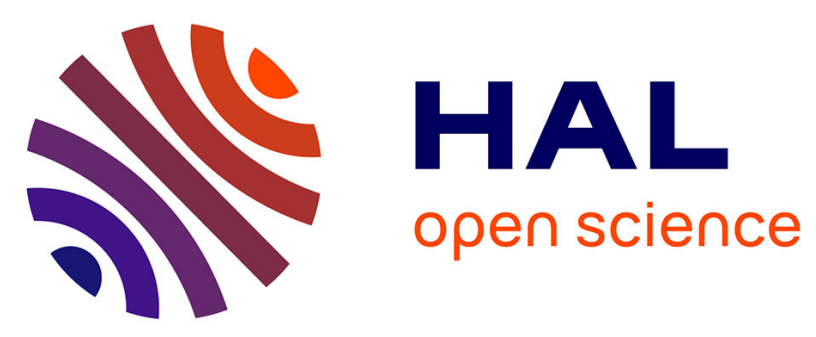

\title{
Detection and quantification of total petroleum hydrocarbons in soils using vegetation optical properties
}

Guillaume Lassalle, Sophie Fabre, Anthony Credoz, Remy Hedacq, Pierre Borderies, Georges Bertoni, Dominique Dubucq, Arnaud Elger

\section{- To cite this version:}

Guillaume Lassalle, Sophie Fabre, Anthony Credoz, Remy Hedacq, Pierre Borderies, et al.. Detection and quantification of total petroleum hydrocarbons in soils using vegetation optical properties. IGARSS 2019, Jul 2019, YOKOHAMA, Japan. hal-02397246

\section{HAL Id: hal-02397246 \\ https://hal.science/hal-02397246}

Submitted on 6 Dec 2019

HAL is a multi-disciplinary open access archive for the deposit and dissemination of scientific research documents, whether they are published or not. The documents may come from teaching and research institutions in France or abroad, or from public or private research centers.
L'archive ouverte pluridisciplinaire HAL, est destinée au dépôt et à la diffusion de documents scientifiques de niveau recherche, publiés ou non, émanant des établissements d'enseignement et de recherche français ou étrangers, des laboratoires publics ou privés. 


\title{
DETECTION AND QUANTIFICATION OF TOTAL PETROLEUM HYDROCARBONS IN SOILS USING VEGETATION OPTICAL PROPERTIES
}

\author{
Guillaume Lassalle ${ }^{a, b}$, Sophie Fabre ${ }^{a}$, Anthony Credoz, Rémy Hédacq ${ }^{b}$, Pierre Borderies ${ }^{a}$, Georges Bertoni $^{c}$, \\ Dominique Dubucq ${ }^{d}$, Arnaud Elger
}

${ }^{a}$ Office National d'Études et de Recherches Aérospatiales (ONERA), Toulouse, France

${ }^{b}$ TOTAL S.A., Pôle d'Études et de Recherches de Lacq, Lacq, France

${ }^{\mathrm{c}}$ DynaFor, Université de Toulouse, INRA, Castanet-Tolosan, France

${ }^{\mathrm{d}}$ TOTAL S.A., Centre Scientifique et Technique Jean-Féger, Pau, France

${ }^{\mathrm{e}}$ EcoLab, Université de Toulouse, CNRS, INPT, UPS, Toulouse, France

\begin{abstract}
A multiscale study was carried out under natural conditions for assessing the potential of vegetation reflectance to quantify soil Total Petroleum Hydrocarbons (TPH). The spectral signature of Rubus fruticosus L. was measured at leaf and canopy scales on an oil-contaminated site, and used for retrieving leaf pigment contents through inversion of PROSPECT and PROSAIL models. Leaf chlorophyll content was strongly related to soil TPH concentrations $\left(\mathrm{R}^{2} \geq 0.8\right)$, which allowed predicting TPH with good accuracy (RMSE $<4$ g. $\mathrm{kg}^{-1}$ ). The quantification of TPH was also achieved at canopy scale $\left(\mathrm{RMSE}=2.85 \mathrm{~g} \cdot \mathrm{kg}^{-1}\right)$. The proposed method shows promising perspectives for oil prospection and contamination monitoring over vegetated areas. This method is under assessment on airborne hyperspectral images for applications over large scale.
\end{abstract}

Index Terms - hyperspectral remote sensing, oil, vegetation, PROSPECT, PROSAIL, pigment.

\section{INTRODUCTION}

In recent years, the use of hyperspectral remote sensing for detecting soil contamination and prospecting natural oil seepages sparked a growing interest by oil and gas companies [1]. Several approaches have been proposed to detect and quantify oil from airborne and satellite images in the on-shore and off-shore domains. Although these approaches perform well on soils and oceans, they are ineffective in vegetated regions. However, because vegetation can be affected by oil exposure, recent studies proposed detecting oil by tracking alterations in vegetation biochemistry and optical properties [2]. Progress in this field showed that it is possible to detect and discriminate among various oil products in soils (crude oil, diesel, etc.) from leaf and canopy reflectances in the reflective domain, under experimental conditions [3]. The next step of this approach consists in quantifying oil concentration, especially Total Petroleum Hydrocarbons (TPH), which remains a major challenge. To achieve this, previous studies suggested tracking changes in leaf pigment contents using vegetation reflectance, since their alteration depends on the level of exposure to oil [2][3]. However, the application of such approach under natural conditions, on airborne or satellite images, remains uninvestigated.

In this study, we propose a method for detecting and quantifying soil TPH over vegetated areas using hyperspectral remote sensing, which can be applied to airborne or satellite images. This method relies on the retrieval of leaf pigment contents from vegetation optical properties using the PROSPECT and PROSAIL models [4].

\section{MATERIALS AND METHODS}

A field campaign was carried out on summer 2017 on an industrial brownfield contaminated by TPH and colonized by vegetation, mainly Rubus fruticosus L. (bramble). Spectral signatures of this species were acquired in the [400:2500] nm spectral domain using a leaf-clip connected to an ASD FieldSpec 4 Hi-Res spectroradiometer (Malvern Panalytical, Malvern, UK), on 23 points of the site (Fig. 1). 3 leaves per point were measured this way and soil TPH 
concentrations $\left(16-77 \mathrm{~g} \cdot \mathrm{kg}^{-1}\right)$ were analyzed. Similar measurements were carried out on the same species on a control site, where no TPH were found. Leaf biochemical parameters were estimated from the spectral signatures by inverting the PROSPECT model, following the procedure described in [5]. PROSPECT simulates the spectral signature of leaves from their anatomical and biochemical parameters (including pigment, water and dry matter contents) [3]. Inversion of the model allows retrieving these parameters from measured spectral signatures, using an iterative optimization approach. Chemical analyses were carried out on leaves to assess biochemical parameters estimated by the model, using the $\mathrm{R}^{2}$ and the Root Mean Squared Error (RMSE) [5]. The retrieved leaf pigment contents were compared between the two sites (brownfield and control) using ttest. Within the brownfield, pigment contents were thereafter linked to soil TPH concentrations. $50 \%$ of the data ("train set") were used to calibrate univariate regression models, and the remaining $50 \%$ ("test set") to assess TPH predictions. The predicted concentrations were compared to those of soil analyses on the test set using the $\mathrm{R}^{2}$ and the RMSE.

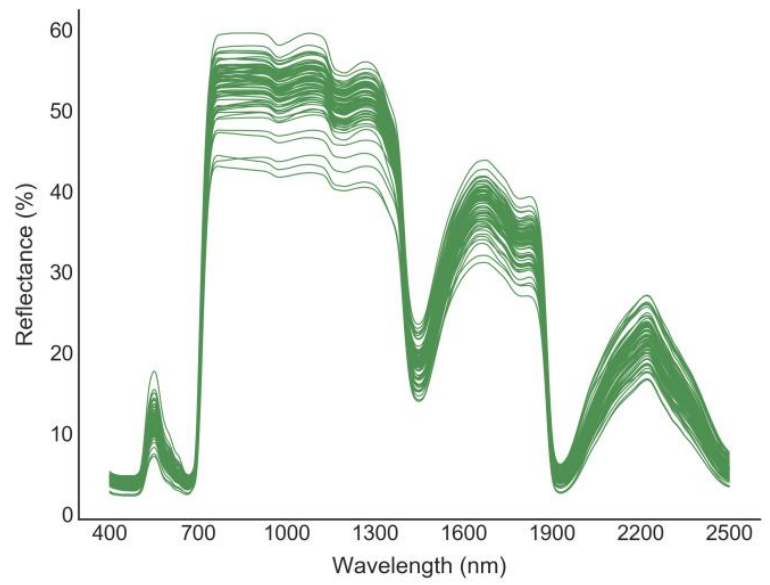

Figure 1. Spectral signatures of bramble leaves measured on the 23 plots on summer 2017.

In addition, the method was assessed simultaneously at leaf and canopy scales on the same period. 10 plots of approximately $16 \mathrm{~m}^{2}$ with known soil TPH concentrations $\left(17-39 \mathrm{~g} \cdot \mathrm{kg}^{-1}\right)$ were defined. 18 and 9 spectral signatures were acquired on each plot at leaf and canopy scales, respectively. A $25 \mathrm{~mm}$-wide fore optics placed $30 \mathrm{~cm}$ above the target at nadir was used for canopy measurements. Data were acquired in radiance and converted to reflectance using a white calibration panel [3]. Leaf biochemical parameters were estimated from leaf and canopy spectral signatures by inverting the PROSPECT and PROSAIL models, respectively. The PROSAIL model extends the use of PROSPECT to canopy measurements by accounting for the influence of vegetation structure and bare soil fraction. A planophile leaf inclination distribution function was used for inverting PROSAIL [6]. The spectral signature of bare soil was also acquired and used in PROSAIL inversions. For both PROSPECT and PROSAIL inversions, the parameters (pigments, water, LAI, etc.) were estimated within bounds typically found in the literature [4]. Leaf pigment contents retrieved from leaf (PROSPECT) and canopy (PROSAIL) measurements were linked to soil TPH concentrations using the procedure described above.

As a perspective of application, airborne hyperspectral images were acquired over the same study site on summer 2017. These acquisitions were carried out using HySpex VNIR-1600 and SWIR-320m-e cameras (Norsk Elektro Optikk AS, Lørenskog, Norway), with a spectral resolution of 3.7 and $6 \mathrm{~nm}$, respectively. The images served for validating the proposed method over a large vegetated area.

\section{RESULTS AND DISCUSSION}

The PROSPECT model performed well for retrieving leaf biochemical parameters from the spectral signatures, especially chlorophylls $\left(\mathrm{R}^{2}=0.92\right.$ and $\mathrm{RMSE}=2.65 \mu \mathrm{g} \cdot \mathrm{cm}^{-2}$ ). Variations in these parameters explained the variability of reflectance observed within the brownfield (Fig. 1). Leaf mean chlorophyll content was significantly different between the brownfield and the control site $(\mathrm{p}<0.05)$. A similar trend was observed on leaf carotenoid content. These alterations in leaf pigments and reflectance under exposure to TPH are consistent with previous work carried out under controlled conditions [2][3]. Our results show that these alterations also occur under natural conditions, which allow detecting TPH. 
Leaf pigment contents were strongly related to TPH concentrations on the 23 points of the brownfield, especially chlorophylls $\left(\mathrm{R}^{2}=0.89\right)$ (Fig 2a). As a result, TPH were predicted with good accuracy (RMSE $=3.63 \mathrm{~g} \cdot \mathrm{kg}^{-1}$ ), especially for concentrations below 30 g. $\mathrm{kg}^{-1}$ (Fig. 2b). Predictions were less accurate using leaf carotenoid content $(\mathrm{RMSE}=8.31$ g. $\mathrm{kg}^{-1}$ ), because the different carotenoid pigments ( $\beta$ carotene, lutein, etc.) are not affected in the same way by exposure to TPH [3]. These results are consistent with previous work linking pigment-related vegetation

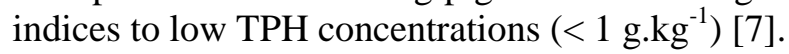
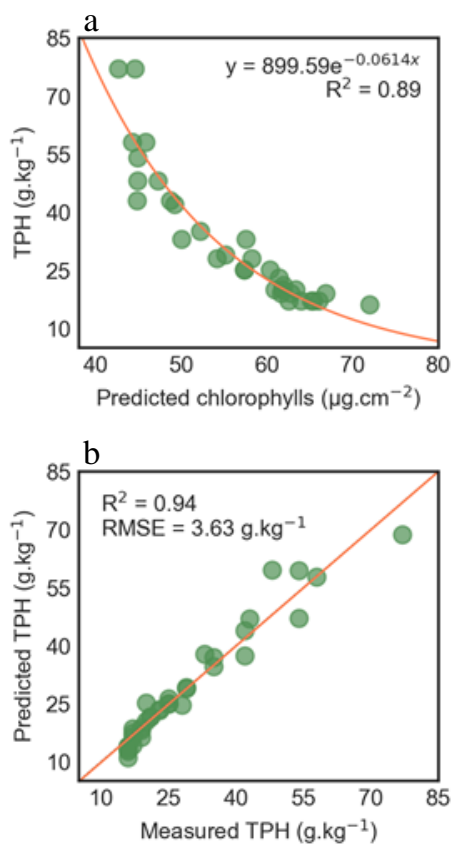

Figure 2. (a) Relationship between leaf chlorophyll content and soil TPH concentrations (train set). (b) Comparisons between predicted and measured soil TPH concentrations (test set).

The results obtained on the 23 points were confirmed at leaf and canopy scales on the 10 plots. Because TPH affect vegetation growth, the spectral signature measured at canopy scale strongly differed from that of leaves, as described in previous work [2][3]. However, because PROSAIL accounts for the influence of ground cover, leaf pigment contents estimated from the spectral signatures at canopy scale were consistent with those obtained at leaf scale using PROSPECT (Fig. 3a). Therefore, a similar relationship with TPH concentrations was observed at leaf and canopy scales $\left(\mathrm{R}^{2}=0.87\right.$ and 0.84 , respectively) (Fig. $3 \mathrm{~b})$. This resulted in accurate estimations of TPH $\left(\mathrm{RMSE}=2.62\right.$ and $2.85 \mathrm{~g} \cdot \mathrm{kg}^{-1}$ at leaf and canopy scales, respectively) (Fig. 3c). Previous work showed that TPH-induced alterations in pigments can be detected from leaf to canopy scale using vegetation reflectance, under controlled conditions [2][3]. Our method extends its use to the quantification of TPH under natural conditions and opens up promising perspectives for applications at larger scale.
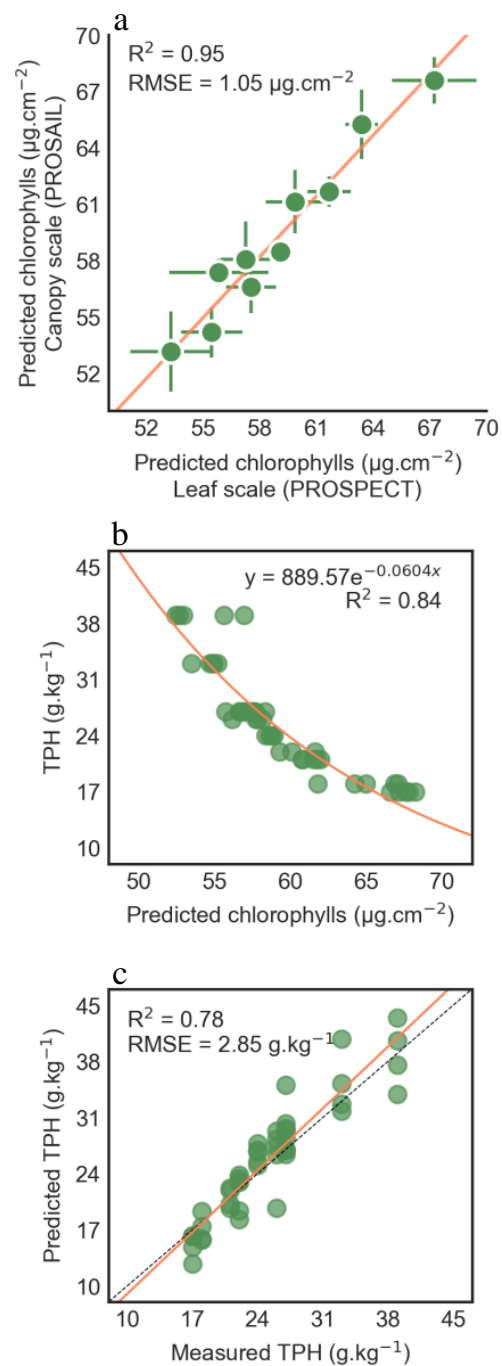

Figure 3. (a) Comparisons between leaf chlorophyll contents predicted from leaf or canopy spectral signatures using PROSPECT and PROSAIL, respectively. (b) Relationship between leaf chlorophyll content estimated at canopy scale and soil TPH concentrations (train set). (c) Comparisons between predicted and measured soil TPH concentrations at canopy scale (test set).

\section{CONCLUSION}

This study demonstrates that soil TPH can be detected and quantified from vegetation reflectance by tracking 
alterations in leaf pigment contents through inversions of PROSPECT and PROSAIL models. The proposed method proved to be robust from leaf to canopy scale. This method is currently assessed on the airborne images with high spatial and spectral resolutions acquired over the same study site (Fig. 4). This step represents a major challenge for operational oil prospection and monitoring applications.

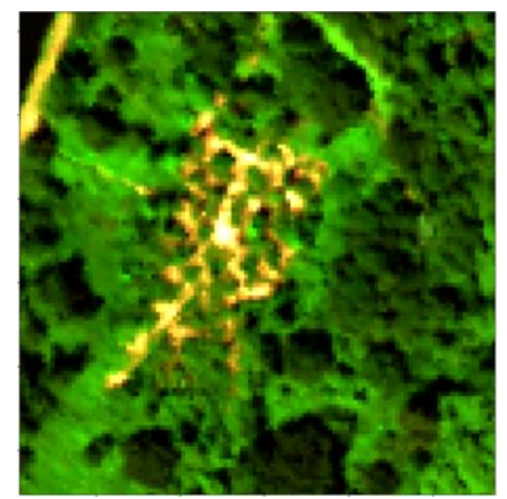

Figure 4. Subset of the airborne hyperspectral acquired over the study site on summer 2017 for assessing the proposed method.

\section{AKNOWLEDGEMENTS}

This work is part of the NAOMI project between TOTAL and the ONERA, with the support of Ecolab and Dynafor research units of Toulouse. Financial support of this work was provided by TOTAL.

\section{REFERENCES}

[1] R. D. P. M. Scafutto, C. R. de Souza Filho, and W. J. de Oliveira, "Hyperspectral remote sensing detection of petroleum hydrocarbons in mixtures with mineral substrates: Implications for onshore exploration and monitoring," ISPRS J. Photogramm. Remote Sens., vol. 128, pp. 146157, 2017.

[2] I. D. Sanches et al., "Assessing the impact of hydrocarbon leakages on vegetation using reflectance spectroscopy," ISPRS J. Photogramm. Remote Sens., vol. 78, pp. 85-101, 2013.

[3] G. Lassalle et al., "Science of the Total Environment Detection and discrimination of various oil-contaminated soils using vegetation reflectance," Sci. Total Environ., vol. 655, pp. 1113-1124, 2019.
[4] S. Jacquemoud et al., "PROSPECT + SAIL models: A review of use for vegetation characterization," Remote Sens. Environ., vol. 113, no. SUPPL. 1, pp. S56-S66, 2009.

[5] P. Li and Q. Wang, "Retrieval of leaf biochemical parameters using PROSPECT inversion: A new approach for alleviating ill-posed problems," IEEE Trans. Geosci. Remote Sens., vol. 49, no. 7, pp. 2499-2506, 2011.

[6] R. Balandier et al., "Architecture, cover and light interception by bramble (Rubus fruticosus): A common understorey weed in temperate forests," Forestry, vol. 0, pp. 1-8, 2012.

[7] L. Zhu et al., "Soil TPH Concentration Estimation Using Vegetation Indices in an Oil Polluted Area of Eastern China". PLoS ONE, 8(1), e54028. 